\title{
Using Group Therapy to Resolve Social Adjustment Problems of Sojourner Students at Universitas Indonesia
}

Fadhilah Amalia $^{\mathrm{a}}$, Lathifah Hanum, ${ }^{\mathrm{b}^{*}}$ and Augustine Dwi Putri Sukarlan ${ }^{\mathrm{b}}$

${ }^{a}$ Faculty of Psychology, Universitas Indonesia, Depok, Indonesia; ${ }^{b}$ Clinical Psychology Department, Faculty of Psychology, Universitas Indonesia, Depok, Indonesia.

*Corresponding Author:

Lathifah Hanum

Clinical Psychology Department

Faculty of Psychology, Universitas Indonesia

Jl. Lkr. Kampus Raya, Depok, Jawa Barat

Indonesia, 16424

Tel.: +62 217270004

e-mail address: lathifah.hanum08@ui.ac.id 


\title{
Using Group Therapy to Resolve Social Adjustment Problems of Sojourner Students at Universitas Indonesia
}

\begin{abstract}
This research was conducted to study the effect of group therapy using a cognitive behavioral approach to improve social adjustment of sojourner students at Universitas Indonesia. Social self-efficacy is known as a trait that can affect social adjustment. Some student's problems with social interaction had a negative impact and became a severe psychological problem. Therefore, psychological intervention was required to solve the social adjustment problem by increasing social self-efficacy of sojourner students at Universitas Indonesia. This research used a quasi-experimental design as its method with one group pre-post-test design, by providing group therapy for five participants. The goal of the group therapy was to improve social self-efficacy for sojourner students, which can also be seen in behavior and cognitive aspects. The results of this study measured quantitatively using perceived social self-efficacy (PSSE, Smith and Betz 2003) shows an increase of social self-efficacy in all of the participants. Through qualitative data, the results indicate that cognitive and behavioral aspects changed in all of the participants. The updated cognitive aspects show a changed belief about their own self-efficacy; participants were able to successfully dispute their negative thoughts so that they would have more rational responses. Behavioral aspects show that their behavior in social interactions changed, especially with regard to the initiative of making social contact and joining groups. This research also indicates that using group therapy has advantages for all participants due to the therapeutic effect of learning from other group member's experiences.
\end{abstract}

Keywords: Cognitive-Behavioral Approach; group therapy; social self-efficacy; social adjustment; sojourner student

\section{Introduction}

According to the Higher Education Data Sources DIKTI (2010), universities with high-quality education programs in Indonesia are not yet widely distributed. Universitas Indonesia is one of the favorite universities for high school students, including for those from outside the Greater Jakarta area (Jabodetabek). In 2015, the UI Freshman Students Health Examination Report reported that UI accepted $31 \%$ of its first-year students from outside the Greater Jakarta area (Klinik Satelit UI, 2015). This data indicates that UI has a high number of sojourner students. Students who leave their hometown to travel to a new area for a period of time to pursue an education are called sojourner students (Church, 1982; Cox, 1988). According to Pedersen (1991), sojourner students face more challenges than local students; one significant one is related to social adjustment. The changes that sojourner students must navigate successfully often cause them to feel pressured and are prone to causing other psychological problems.

Social adjustment for sojourner students is also related to how they perform academically. According to Russel and Thomson (2010), sojourner students may feel more at ease in completing their academic tasks when they feel more comfortable in their new environment and have a peer group as their social support. We also found this condition to be the case in UI students based on data from the Students Consultation Center of Universitas Indonesia. Feelings of discomfort during social interaction, trying to forge new friendships, and participating in 
group work with new people may also affect the individual's ability to complete academic tasks due to decreasing motivation. Furthermore, many of the sojourner students also seek professional help and need counseling services. In general, their complaints are about self-adjustment problems, such as culture shock, homesickness, and difficulties in interpersonal relationships.

According to Barry and Madsen (2010; cited in Arnett, 2012), sojourner students who are entering the emerging adulthood phase perceived that interpersonal relations and friendship are primary needs; where an individual interacts more with peers, the presence of friends may become the main source of support. Pedersen (2011) added that if the need to forge interpersonal relationships is not fulfilled, it may lead to psychological problems such as loneliness, anxiety, and depression. Therefore, social interaction problems in sojourner students may lead them to experience psychological problems that are likely to disrupt their social adjustment.

As an individual enters a new social environment, their self-adjustment is influenced by their individual level of self-efficacy (Hechanova-Alampay, Beehr, Christiansen, \& Van Horn, 2002). Furthermore, the broad concept of self-efficacy can be narrowed to social self-efficacy to fit the context of this research. Social self-efficacy is an individual's belief in her ability to be involved in and successful at social interaction, including starting and maintaining interpersonal relationships (Smith \& Betz, 2000). An individual with a high social self-efficacy is reported to be more capable of adjusting to a new environment and forging relationships within his surroundings than an individual with a low social self-efficacy (Harrison, Chadwick, \& Scales, 1996). In fact, a low social self-efficacy can worsen problems of social interaction because there is a tendency for avoidance and a focus on being worried about social rejection (Smith \& Betz, 2000). According to research by Early and Ang (2003), sojourner students with a higher selfefficacy can actively find new and useful strategies to deal with a new environment, which has new culture value.

Considering the importance of social self-efficacy toward sojourner students' social adjustment in new social environments, we assume that a suitable psychological intervention technique to overcome that problem is required. One of the psychological interventions related to social selfefficacy that has been found effective is Cognitive Behavioral Group Therapy (CBGT), which includes behavior practice, from Gaudiano and Herbert (2003). Gaudiano and Herbert (2003) incorporated a cognitive approach using cognitive restructuring and practicing behavior for individuals with anxiety problems by role-playing in social situations. This technique was found to be more efficient at increasing self-efficacy in social situations for individuals with social anxiety than administering cognitive behavior therapy (CBT) alone (Gaudiano and Herbert, 2003).

Based on the research from Gaudiano and Herbert (2003), we believed that providing interventions using both cognitive and behavioral approaches and conducted in groups could increase social self-efficacy of sojourner students. According to Bandura (1977), the cognitive process is essential because of the need for expected behavioral change; the individual must change his belief about his ability in order to be successful. Furthermore, in behavioral approaches with social skills training, participants apply simple social interactions during the intervention, where the individual's success in completing the given exercises (personal accomplishment) may also contribute to increasing the individual's self-confidence (Bandura, 
1997). Also, using group intervention for implementation creates a place that allows participants with social adjustment problems to practice interacting with other group members; this is considered a "natural laboratory" (Heimberg and Becker, 2003).

Meanwhile, studies about psychological intervention to increase social self-efficacy and social adjustment are still limited. Studies with psychological interventions for improving student selfconfidence in social interaction have been done by Damer, Latimer \& Porter (2010), through the Build Your Social Confidence (BYSC) intervention program. The BYSC program is conducted in group settings using a cognitive-behavioral approach. As mentioned earlier, group intervention using cognitive behavioral methods can increase social self-efficacy, and this goal aligns with the BYSC program; we considered using the BYSC intervention approach with modification for this study.

Based on the description above, the research problem for this study is "Will the application of group therapy using a cognitive-behavioral approach increase the social self-efficacy of sojourner students in Universitas Indonesia (UI)?" Our hypothesis is that the application of group therapy using a cognitive-behavioral approach will increase the social self-efficacy of sojourner students in UI. Furthermore, we expect to see an improvement in cognitive aspects such as the ability to control negative thoughts about engaging in social interaction and in behavioral aspects such as trying to start small conversations with friends. Consequently, this therapy will also assist with the social adjustment problems they are experiencing. Therefore, the objective of this study is to examine the effect of the application of group therapy on the social self-efficacy levels of sojourner students in UI.

\section{Methods}

\section{Participants}

We obtained participants through open recruitment; that is, by spreading information through chats and messenger apps, as well as by contacting and submitting information to community groups in Universitas Indonesia. From the recruited individuals, we selected participants using a non-probability sampling method, accidental sampling technique. We also conducted a selection process to screen potential participants who matched the study criteria. The participants' criteria for this study were as follows: sojourner students in Universitas Indonesia enrolling in the bachelor's program, entering their sophomore year, and having no prior experience of leaving home. We chose sophomore students based on the reasoning that by the end of their freshman year, sojourner students are expected to have already achieved the acceptance stage in the adjustment process (Zeller \& Mosier, 1993). If a sojourner student still has social adjustment problems in his second year, it is seen as a problem that should receive further treatment. Moreover, potential participants needed to score below 75 on the Perceived Social Self-Efficacy (PSSE) (Smith \& Betz, 2000), and be experiencing social adjustment problems; they also had to express the willingness to participate in the group therapy.

Open recruitment was available for two weeks, during which 21 students signed up. Ten of them did not meet the requirements, leaving 11 available potential participants. Three of these were still in their freshman year; one had experienced being a sojourner before; and one person was unreachable. So, out of 11 potential participants, six people met the criteria. We interviewed 
these six about the social adjustment problems they were experiencing and asked for their consent to be involved in this study. They consented; thus, at the beginning of the intervention, we had six participants. During this study, one participant did not complete the intervention program. Therefore, only 5 participants were enrolled in the intervention program from beginning until completion, so only these five were evaluated for this study, using both qualitative and quantitative means.

\section{Research Design}

This study uses the quasi-experimental method with the one group pre-post-test design, where there is only one treatment group that received group therapy using the cognitive-behavioral approach. In this research design, we also observed and evaluated the measured variable of social self-efficacy prior to and after the intervention. Quantitative measurements were conducted using the Perceived Social Self-Efficacy (PSSE) instrument adapted from Smith \& Betz (2000). The PSSE consists of 25 items that show individual behaviors in a social situation. The range of scores from this instrument is $25-125$. This study used a score of 75 as a cut-off for selecting participants. In addition, qualitative results were obtained from the participants through the observation and interview method.

\section{Procedure}

There were three main stages in this study: preparation, implementation, and evaluation. During the preparation stage, we conducted the literature study and prepared the measuring tool. We continued with the participant selection process, beginning with disseminating the recruitment information, then selecting the candidates and performing initial interviews with participants who met the criteria. We also prepared the intervention program by modifying the BYSC program from Damer, Latimer, \& Porter (2010) and arranged for the location and room we would use for the intervention program. After all components in this stage were completed, the study continued to the implementation stage.

The group intervention program for sojourner students in UI with social adjustment problems using cognitive-behavioral approach was conducted over 6 sessions. Sessions were held once a week with an interval between meetings ranging from 5-7 days, with one exception. Between the fourth and fifth sessions, sessions were conducted only three days apart, with the reasoning that the exercise material given in the fourth session was related to the material for the fifth session. Meanwhile, between the fifth and sixth (last) session, the interval was one week. Hence, participants were given a period of time in which to apply the assigned materials and exercises to their daily lives. Overall, the intervention was conducted over five weeks. The duration of each session was approximately 90-120 minutes without any breaks. This group intervention was based on the modification of the BYSC (Build Your Self Confidence) program by Damer, Latimer \& Porter (2010). A few parts were modified to adjust to the needs of and expected target for this particular group. The explanation for the differences between the original BYSC module and the group intervention program used for this study can be found in Table 1 . 
Table 1.

Modification of the BYSC program (Damer, Latimer \& Porter, 2010)

\begin{tabular}{|c|c|c|}
\hline Aspect & BYSC & Group Therapy (BYSC Modification) \\
\hline Treatment component & $\begin{array}{l}\text { Cognitive restructuring, exposure, } \\
\text { assertiveness and social skill training }\end{array}$ & Cognitive restructuring and social skill exercises \\
\hline $\begin{array}{l}\text { The number of times and } \\
\text { duration of session }\end{array}$ & Eight sessions in eight weeks & Six sessions in five weeks \\
\hline Focus on the intended problem & $\begin{array}{l}\text { General problems for students who experience } \\
\text { anxiety in social situations }\end{array}$ & $\begin{array}{l}\text { Specific problem of difficulty engaging in social } \\
\text { interaction due to an individual's low level of } \\
\text { confidence in his ability in social interaction }\end{array}$ \\
\hline Given materials & $\begin{array}{l}\text { - Psychoeducation about social anxiety } \\
\text { - Cognitive restructuring } \\
\text { - Basic skills for conversations, such as the } \\
\text { ability to listen and self-disclosure } \\
\text { - Assertiveness training with the assertive } \\
\text { theme of defense of the self } \\
\text { - Exercise in starting and being involved in } \\
\text { a conversation } \\
\text { - Exercise in conversing in a group setting } \\
\text { with the objective of forging new } \\
\text { friendships } \\
\text { - Exercise in public speaking }\end{array}$ & $\begin{array}{l}\text { - Psychoeducation about self-confidence in the } \\
\text { ability to interact with others } \\
\text { - Cognitive restructuring } \\
\text { - Exercise in starting and being involved in a } \\
\text { conversation } \\
\text { - Exercise in conversing to forge a new } \\
\text { friendship } \\
\text { - Exercise in expressing one's thoughts in a } \\
\text { group discussion }\end{array}$ \\
\hline
\end{tabular}

With regard to the modification of the group intervention program for this study, we selected only activities and materials which are typically used to increase social self-efficacy. There is more cognitive restructuring material in the modification than in the original BYSC program because cognitive aspects are considered essential to improving social self-efficacy. Not all of the social skill materials and exercises from the BYSC program were given to this intervention group. The social skill materials and exercises selected for this group focused on conversations and expressing one's thoughts in a group setting. This was based on the assumption that the problems of many sojourner students revolved around those specific challenges. Public speaking exercises were not included because it was not the primary target of improvement for this intervention, which aimed to focus on daily fundamental social interaction issues. The modifications and adjustments in the group intervention design based on behavior therapy can be found in Table 2.

\section{Data Analysis}

Data analysis in this study uses the qualitative and quantitative method. Using the qualitative approach, we evaluated changes in the cognitive and behavioral aspects of each participant prior to and after the intervention. Before the intervention began, we conducted an initial interview to learn details about the participant's social self-efficacy, especially with regard to the cognitive and behavioral aspects. During the intervention, we gave the participants the task of measuring the changes between sessions. At the end of the intervention, we asked the participants to fill out a final evaluation form and participate in a group discussion about the progress they made during the intervention.

We also conducted additional data analysis using the quantitative method. This data analysis was done to acquire accurate data about the impact of the intervention on the participants' social self- 
efficacy levels. For that purpose, we compared each participant's social self-efficacy score prior to and after the intervention. We used the Wilcoxon sign-ranked statistical test to compare social self-efficacy scores and to examine whether there was a significant change in participants' scores. Both quantitative and qualitative data analysis types will provide the basis for examining the effect of providing a group intervention program for sojourner students with social adjustment problems in UI.

Table 2.

Group Therapy Program for Sojourner Students in UI

\begin{tabular}{|c|c|}
\hline Session & Objective \\
\hline $\begin{array}{l}\text { Pre-session } \\
\text { (Individual) }\end{array}$ & $\begin{array}{l}\text { To gain an idea about participants' social adjustment problems and their social } \\
\text { self-efficacy }\end{array}$ \\
\hline $\begin{array}{l}\text { Session } 1 \\
\text { Opening group, to understand the problem and } \\
\text { psychoeducation }\end{array}$ & $\begin{array}{l}\text { Participants feel comfortable in a group setting by showing open attitudes } \\
\text { Participants understand the dynamics of social adjustment, which they } \\
\text { experienced, and the importance of social self-efficacy to their adjustment process. }\end{array}$ \\
\hline $\begin{array}{l}\text { Session } 2 \\
\text { To understand negative thoughts about one's self- } \\
\text { confidence through the ABC model }\end{array}$ & $\begin{array}{l}\text { Participants can identify negative thoughts and identify them using the ABC } \\
\text { model }\end{array}$ \\
\hline $\begin{array}{l}\text { Session } 3 \\
\text { Using the ABCDE concept in shaping confidence } \\
\text { about one's ability }\end{array}$ & $\begin{array}{l}\text { Participants can use the overall ABCDE concept and understand its effect on self- } \\
\text { confidence in forging social relationships }\end{array}$ \\
\hline $\begin{array}{l}\text { Session } 4 \\
\text { Exercise in starting and being involved in a } \\
\text { conversation }\end{array}$ & $\begin{array}{l}\text { Participants can increase their efficacy in communications and boost their self- } \\
\text { confidence through their success in engaging in a conversation }\end{array}$ \\
\hline $\begin{array}{l}\text { Session } 5 \\
\text { Exercise in forging social contact and expressing } \\
\text { one's opinion in a group setting }\end{array}$ & $\begin{array}{l}\text { Participants can practice ways of forging social contact or new friendships and } \\
\text { expressing their opinions in a group setting. }\end{array}$ \\
\hline $\begin{array}{l}\text { Session } 6 \\
\text { Closing and termination }\end{array}$ & $\begin{array}{l}\text { Therapist and participants can see the changes and growth in participants' self- } \\
\text { confidence about their efficacy in starting and maintaining relationships during the } \\
\text { session. }\end{array}$ \\
\hline
\end{tabular}

\section{Results}

The results of this study indicate that a group intervention program using a cognitive-behavioral approach may increase social self-efficacy and help participants face social adjustment problems as sojourner students, especially within social interactions. As seen in Table 3, the results indicate a change in the group mean score prior to and after the intervention. The Wilcoxon signranked statistical test also indicates a significant effect.

Table 3.

Total Mean Score Difference of Pre-Post Test and the Wilcoxon Sign-Ranked Statistical Test

\begin{tabular}{llllll}
\hline Variable & Minimum & Maximum & Mean & Z & Sig. \\
\hline PSSE Pre-Intervention & 48 & 68 & 57,2 & $-2,023$ & 0,043 (2-tailed) \\
PSSE Post-Intervention & 69 & 82 & 76 & & \\
Group changes: $32,8 \%$ & & & & & \\
\hline
\end{tabular}

As seen in Table 3, the total mean score for sojourner students' social self-efficacy after the group intervention program was higher than the total mean score before the group intervention. The increase of the total mean score was quite high, at $32.8 \%$. 
To calculate the total mean scores, we conducted a Wilcoxon signed-rank statistical test to find out whether there was a significant change in the social self-efficacy score after conducting the group intervention. According to the test result, the value of $Z$ obtained was $-2,023, p(0,043)<$ 0,05 . This result indicates a significant difference between the social self-efficacy score in the pre-test before the intervention and the post-test after the intervention for the sojourner students. This test result also indicates that the group intervention program affects the levels of social selfefficacy for the sojourner students. From this test, the intervention seems to have increased the level of social self-efficacy for the sojourner students in UI.

From the participants' social self-efficacy scores, there is an indication that each participant experienced a score increase with different, individual marks. These differences can be seen in Figure 1 and Table 4.

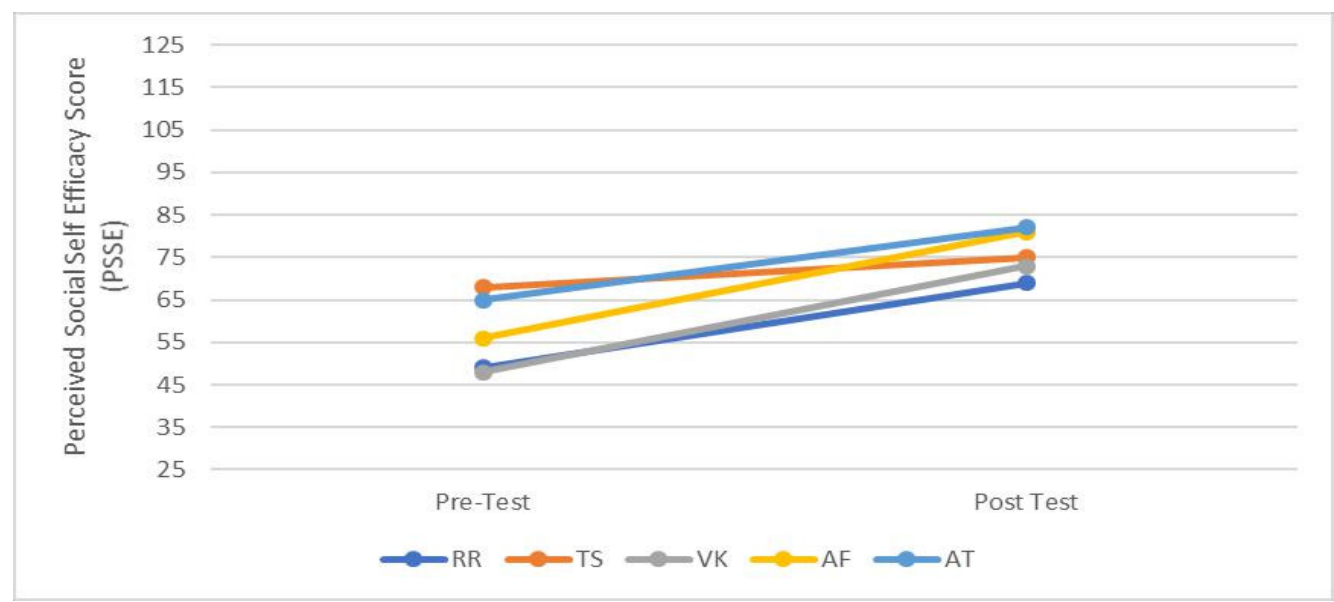

Figure 1. Measurement Result of PSSE Before and After Group Intervention

Table 4.

Range of Changes in Each Participant's PSSE Score

\begin{tabular}{ccccc}
\hline Participant & $\begin{array}{c}\text { Result Before Group } \\
\text { Therapy }\end{array}$ & $\begin{array}{c}\text { Result After Group } \\
\text { Therapy }\end{array}$ & Result Difference & Changes (\%) \\
\hline RR & 49 & 69 & 20 & $40,8 \%$ \\
TS & 68 & 75 & 7 & $10,2 \%$ \\
VK & 48 & 73 & 25 & $52,1 \%$ \\
AF & 56 & 81 & 25 & $44,6 \%$ \\
AT & 65 & 82 & 17 & $26,1 \%$ \\
\hline
\end{tabular}

As seen in Figure 1 and Table 4, the change in participants' PSSE scores ranged between 7-25 points. The highest number indicates the most change at 25 points or $52.1 \%$; this score belonged to $\mathrm{VK}$, who received the lowest score on his social self-efficacy measurement before the group intervention. On the other end of the spectrum, TS, who scored the highest among participants before the intervention, only increased by 7 points or $10.2 \%$. 
Aside from changes that can be seen in the quantitative analysis, the benefit of the group intervention can be seen in the qualitative data as shown in Table 5. All participants experienced changes in the cognitive aspect, such as recognizing and understanding negative thoughts that cause self-confidence to decline while engaging in social interaction. Four out of five participants reported that they could feel the benefit of the ABCDE concept on their selfconfidence when engaging in social interaction. From a behavioral aspect, all five participants were starting to express their opinions more openly. Three of them have already been brave enough to start a conversation with the intention of forging a new friendship.

Table 5.

The Participants' Condition Post Intervention

\begin{tabular}{|c|c|c|}
\hline \multirow[t]{2}{*}{ Participant } & \multicolumn{2}{|c|}{ Post-Intervention Changes } \\
\hline & Cognitive & Behavior \\
\hline RR & $\begin{array}{l}\text { - Recognizes that negative thoughts must be managed to } \\
\text { maintain a favorable social interaction } \\
\text { - Identifies the potential of forging relationships } \\
\text { - More sure about his self-confidence by understanding that } \\
\text { the important thing in a relationship is the courage to start } \\
\text { one }\end{array}$ & $\begin{array}{l}\text { - Starts to open up in expressing opinions and } \\
\text { thoughts in a group setting } \\
\text { - Begins to show courage in starting a conversation } \\
\text { with a friend } \\
\text { - Offers jokes or small talk }\end{array}$ \\
\hline TS & $\begin{array}{l}\text { - Recognizes negative thoughts and can counter them } \\
\text { - Manages ideas when beginning to interact with friends }\end{array}$ & $\begin{array}{l}\text { - Starts to express thoughts and feelings more openly } \\
\text { (affective exploration) }\end{array}$ \\
\hline VK & $\begin{array}{l}\text { - Not all people judge him the same way. Hence some are } \\
\text { still willing to be his friend } \\
\text { - Convinces himself that he can do it } \\
\text { - Counters negative thoughts when trying to start } \\
\text { relationships with other people }\end{array}$ & $\begin{array}{l}\text {-Beginning a short conversation with a peer at } \\
\text { campus } \\
\text {-Involved and active in the group } \\
\text {-Attempts to enter a peer group }\end{array}$ \\
\hline $\mathrm{AF}$ & $\begin{array}{l}\text { - Recognizes that negative thoughts cause incorrect behavior } \\
\text { in relationships } \\
\text { - Convinces himself to be brave to start }\end{array}$ & $\begin{array}{l}\text {-Expresses opinions within the group } \\
\text {-Involves himself to be more active in group work }\end{array}$ \\
\hline AT & $\begin{array}{l}\text { - Finds a way to forge social ties } \\
\text { - Recognizes the presence of negative thoughts }\end{array}$ & $\begin{array}{l}\text { - Shows courage by saying something about himself } \\
\text { openly in the intervention program } \\
\text { - Attempts to have conversations with peers in the } \\
\text { campus setting }\end{array}$ \\
\hline
\end{tabular}

\section{Discussion}

In general, participants experienced an increase in their social self-efficacy and social adjustment as sojourner students. The participants' motivation and willingness also affected the process and result. We assume that the increase happened because the form of this intervention program targeted the essential cognitive and behavioral processes needed for successful social selfefficacy. The cognitive approach is considered suitable according to the explanation from Bandura (1997) about the importance of changing one's self-confidence before changing the behavior. Therefore, when participants exercised social interaction in a group setting, it can be said that they were ready because they already felt confident in themselves.

There are several contributing factors which affected the effectiveness of this group intervention for sojourner students. These factors can be examined separately according to whether they were seen in the individual process or the therapeutic group process. The individual factor that seems to be affected the most is closely related to the participants' motivation. According to Bandura 
(1992), an individual who sets a target and decides on the resources which will be used, will be able to feel confidence in his efficacy. The participants' motivation can be seen in how involved they were in the group intervention process and by completing the exercises that would help them. This situation can also be seen in three participants based on social self-efficacy score and qualitative data: VK, RR, and AF experienced many positive changes. These three participants seem to be actively applying the cognitive restructuring exercises when facing daily social interaction challenges.

Significant changes in VK's case were also influenced by the existence of positive experiences with social interaction with friends from the same cultural background. Because of this fact, he seems even more capable of controlling his negative thoughts. Furthermore, RR also worked to find the most suitable way for him to exercise his social interaction efficacy by actively doing self-monitoring exercises. The critical function of this exercise is for participants to be able to monitor themselves so that they adjust to the expected behavior. Participants who possess better self-monitoring are more willing to make behavioral changes to fit within a favorable social situation. (Snyder \& Gangestand, 1986, cited in Hermann, 2005). This finding was different with the student TS, who was evaluated as having the least number of changes out of all participants. TS seemed reluctant to apply the assigned exercises during the intervention session; this could be seen in his attitude about not completing the given tasks seriously. Hence, TS, who also did not do his self-monitoring exercises accurately, also displayed an attitude that affected his willingness to change his behavior.

For the group therapeutic factor, we could see that the primary benefit of the group was the support factor. During the group activities, participants were sharing challenges they all face. The group dynamic process seemed "alive" during these sharing activities. Moreover, we discussed what insights the participants felt they gained to understand the changes experienced in each meeting. There is also a therapeutic factor of psychological work, where every insight from every participant adds to cognitive and behavioral awareness for the whole group, which strengthens changes within individual participants (MacKenzie, 1992). Participants also expressed that they no longer felt alone, and that they felt more appreciated as part of a group. Group therapy can also become a social support for sojourner students, because it can alleviate social adjustment issues that all are facing by garnering affirmation from other people in the group (Pedersen, 1991). The factor of learning from other people or vicarious learning also affected the effectiveness and improvements in the participants.

In the group intervention, there were techniques or materials that affected the effectiveness of the intervention. Almost all of the participants stated that the ABCDE concept or the cognitive restructuring was the most beneficial material and technique. Through cognitive restructuring, participants were able to change their negative thoughts about their self-efficacy in conducting social interactions to more rational responses, also known as active rational responses (Heimberg $\&$ Becker, 2003). This relates to the theory by Bandura (1992), where the cognitive aspect represents the central aspect of change in an individual's self-confidence. Therefore, the ABCDE technique is considered suitable in its direct targeting of the individual's cognitive aspect for increasing their self-efficacy. 
Aside from providing cognitive restructuring, this group intervention program also involved social skill exercises. These exercises allowed participants to practice starting and being involved in a conversation and starting social contact. With these exercises, participants were also able to train themselves directly and prove their own efficacy in forging social interactions. This describes the concept of how the presence of personal accomplishment can become a repetitive source of increasing an individual's self-confidence (Bandura, 1997). From these exercises, participants were able to find they have potential within themselves to engage in social relations, such as involving oneself in a conversation, especially on a topic of interest, or being ready to greet a friend. With these accomplishments, the participants' confidence in their social interaction efficacy will also continue to increase.

In the intervention implementation, there were some limitations. The psychoeducation material given in the first session seemed to be less efficient for the participants who needed more time to adjust to a new environment. Hence, the sharing session could be conducted to ensure that participants feel more comfortable and begin to trust the group. Aside from that, the material given should be simplified. Also, one participant (TG) experienced minimal change as measured by qualitative analysis. This was caused by his prior psychological problem with engaging in social interaction. Because individual characteristics can vary, even group intervention that targets similar issues can be limited in its success in dealing with particular individuals (Heimberg, 2003). Therefore, in exceptional cases, group intervention also needs to be completed along with individual sessions.

There were six sessions in this intervention program. With the objective of increasing selfconfidence in social interactions and initiating social contact, these six sessions seem to have elicited positive changes in the participants from the pre-intervention stage to the postintervention condition. But managing more complex social interaction problems such as forging a close friendship cannot be facilitated by this intervention program. This is because it was not a target for this particular intervention program. According to Brabender, Smolan \& Fallon (2004), the duration of each session is adjustable according to the complexity of the problem. This means that the more complex the problem being targeted, the longer the sessions will need to be. On the other hand, the simple exercises that were conducted seem to have helped the participants manage daily challenges such as starting and being involved in a conversation. With the accomplishment of a targeted behavior, each participant gains high hopes for further change. In fact, the participants in this group requested more social interaction exercises.

Some techniques and materials about self-disclosure and assertiveness should be added because these two materials seem like they would help the participants in this group intervention program. Although we included self-disclosure components and affective exploration in the social skills exercises, this additional material seems especially likely to inform the participants about the steps they can take when feeling challenged by forging closer friendships. Assertiveness materials are also advised to be added to the program, because in general, the participants who have problems in expressing their thoughts in challenging situations would benefit from it. 


\section{References}

Arnett, J.J (2014). Emerging Adulthood: The Winding Road from Late Teens Through the Twenties (2 ${ }^{\text {nd }}$ ed). Oxford: Oxford University Press.

Bandura, A. (1992). Exercise of personal agency through the self-efficacy mechanism. In R.Schwarzer (Ed), Self-efficacy: Thought control of action (pp. 3-38). Washington D.C: Hemisphere

Bandura, A. (1997). Self-efficacy: The Exercise of Control. New York: Cambridge University.

Brabender, V.A., Fallon, A.E., \& Smolar, A. I. (2004). Essentials of Group Therapy. Canada: John Wiley \& Sons.

Church, A. T. (1982). Sojourner Adjustment. Psychological Bulletin: APA. 91(3), 540-572.

Cox, L. J. (1988). The Overseas Student: Expatriate, Sojourner or Settler? Acta Psychiatrica Scandinavica, 78, 179-184.

Damer, D. E., Latimer, K., \& Porter, S. (2010) "Build Your Social Confidence": A Social Anxiety Group for College Students. Journal for Specialist in Group Work. 35 (1), 7-22.

Early, P.C \& Ang, S. (2003). Cultural Intelligence: Individual interactions across culture. CA: Stanford University Press. Harrison, J.K., Chadwick, M. \& Scales, M. (1996). The relationship between cross-cultural adjustment and the personality variables of self-efficacy and self-monitoring. International Journal of Intercultural Relations 20,167-88. Hechanova-Alampay, R., Beehr, T., A., Christiansen, N. D., \& Van Horn, R. K. (2002). Adjustment and Strain among domestic and international student sojourners. School Psychology International. 23; 458-474

Heimberg, R. G. \& Becker, R. E. (2003). Cognitive-Behavioral Group Therapy for Social Phobia. New York: The Guilford Press.

Hermann, K. S. (2005). The Influence of Social self-efficacy, self-esteem, and personality differences on loneliness and depression (Doctoral Dissertation, The Ohio State University). Retrieved from: https://etd.ohiolink.edu/rws_etd/document/get/osu1112104621/inline

Gaudiano, B. A. \& Herbert, J. (2003). Preliminary Psychometric Evaluation of a New Self-Efficacy Scale and Its Relationship to Treatment Outcome in Social Anxiety Disorder. Cognitive Therapy and Research, 27 (5); 537-555.

Klinik Satelit Universitas Indonesia. (2015). The UI Freshman Students Health Examination Report. Unpublished Manuscript. Universitas Indonesia, Depok, Indonesia.

MacKenzie, K.R (Ed). (1992). Classics in group psychotherapy. New York: Guilford

Pedersen, P. B. (1991). Counseling International Students. The Counseling Psychologist. 19; 240-245.

Pedersen, E.R., Neighbors, C., Larimer, Marry. E., \& Lee, C. (2011). Measuring Sojourner Adjustment among American Students studying abroad. International Journal Intercultural Relation. 35 (6); 881-889.

QS World University Rankings (2016). Retrieved from https://www.topuniversities.com/university-rankings/world-universityrankings/2016

Russell, J., Rosenthal, D., \& Thomson, G. (2010). The international student experience: Three styles of adaptation. Higher Education. 60 (2), 235-249.

Smith, H. M., \& Betz, N. E. (2000). Development and validation of a scale of perceived social self-efficacy. Journal of Career Assessment, 8, 283-301.

The Higher Education Data Sources DIKTI. (2010). Retrieved from: https://forlap.ristekdikti.go.id/perguruantinggi

Zeller, W. J \& Mosier, Robert. (1993). Culture Shock and The First Year Experience. Journal of College and University Student Hawking. 23 (2); 43-69 